\title{
Erratum
}

\section{Erratum: Breton et al., Phase Coherent Currents Underlying Neocortical Seizure-Like State Transitions}

In the article "Phase Coherent Currents Underlying Neocortical Seizure-Like State Transitions," by Vanessa Breton, Berj Bardakjian, and Peter Carlen, which was published online on March 7, 2019, there were errors within the axes in Figures 3a3, $9 a 1,9 a 2$, and $12 A$. The authors note that the errors "do not affect the final conclusions drawn, nor any of the calculations made."

In Figure 3a3, the horizontal axis should read 0 to 180.

In Figure 9a1, pseudocolor plot should read, "Frequency of Amplitude Signal (Hz)" on the vertical axis and "Frequency of Phase Signal $(\mathrm{Hz})$ " on the horizontal axis.

In Figure 9a2, the horizontal axis of the top graph should read 118 to 120.

In Figure 12A, the label "140" at the end of the horizontal axis should be removed.

The article has been corrected online.

https://doi.org/10.1523/ENEURO.0145-19.2019

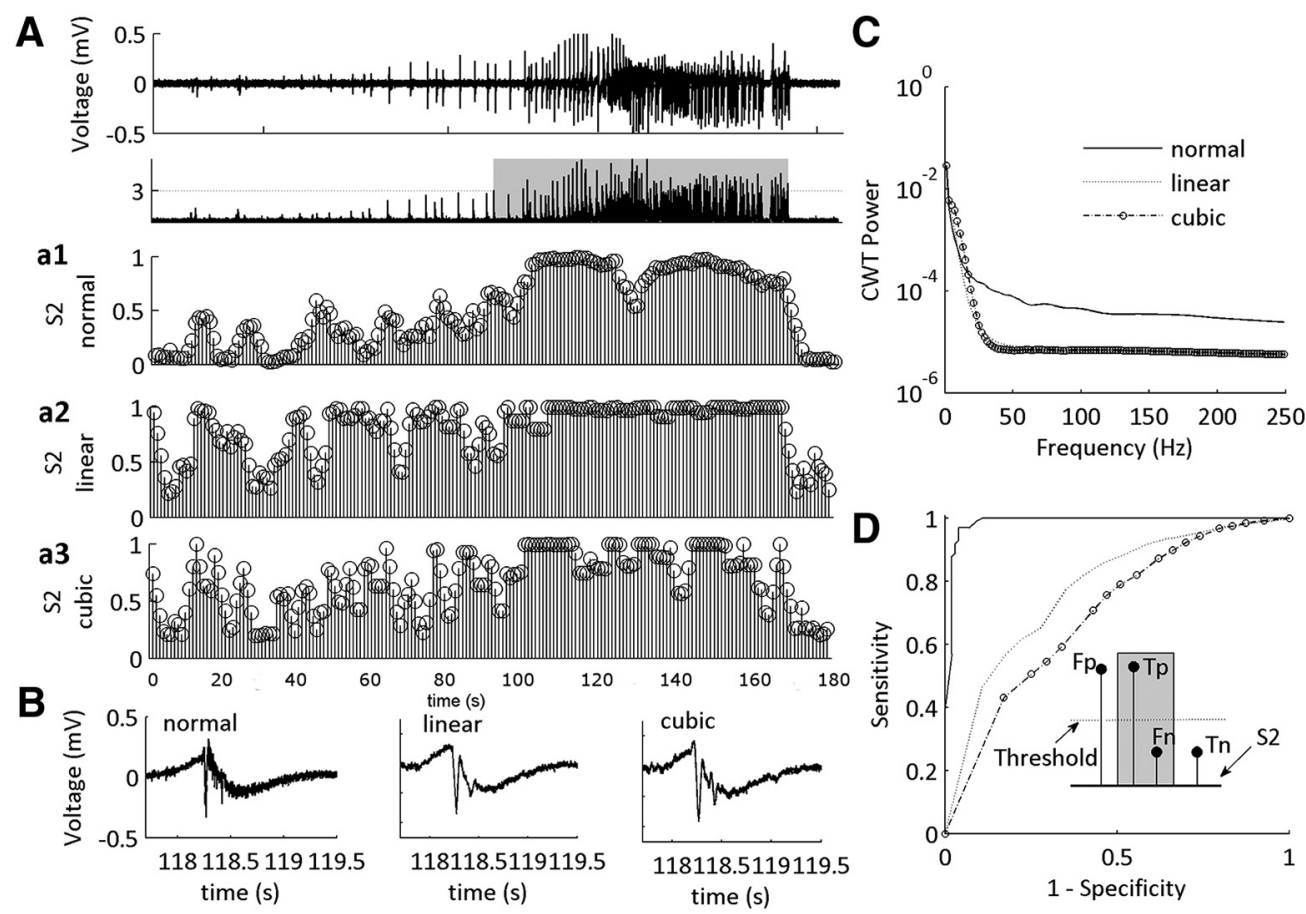

Figure 3. 
A
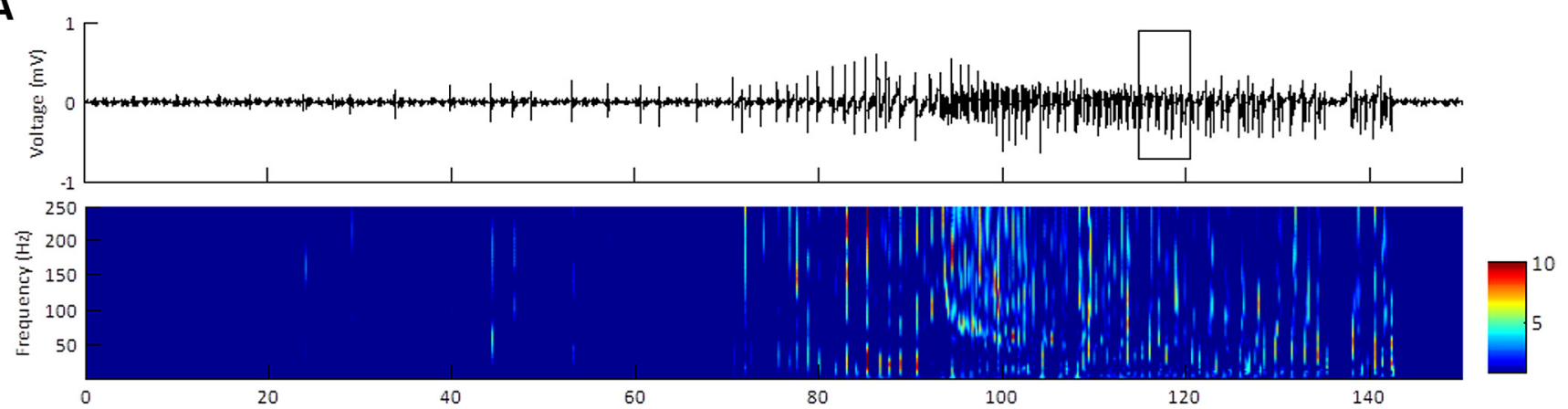

a1
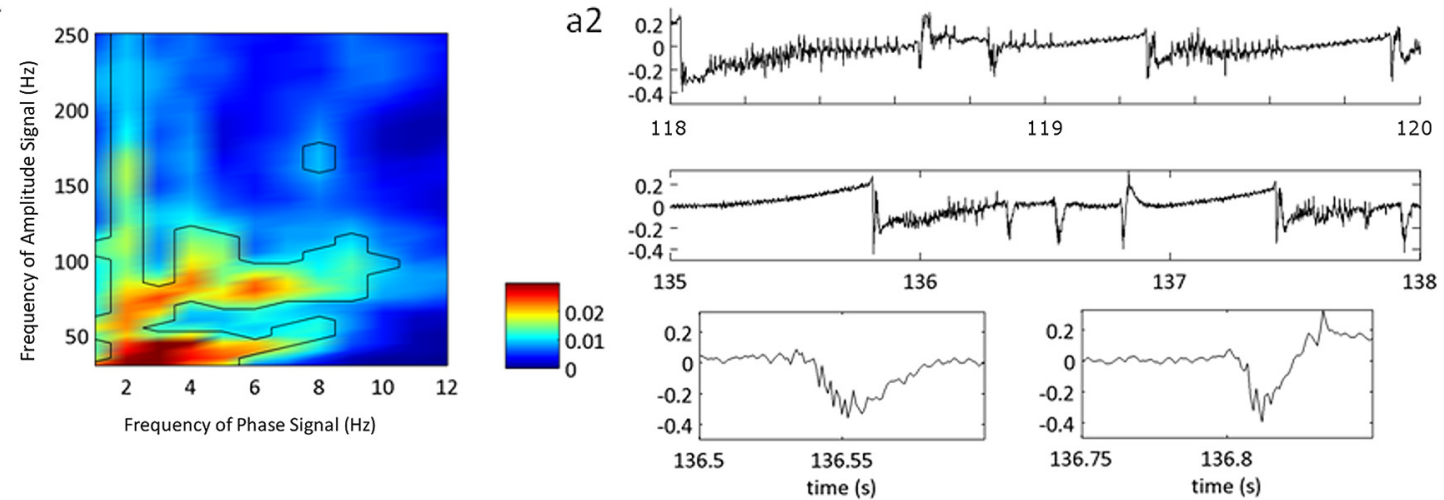

B

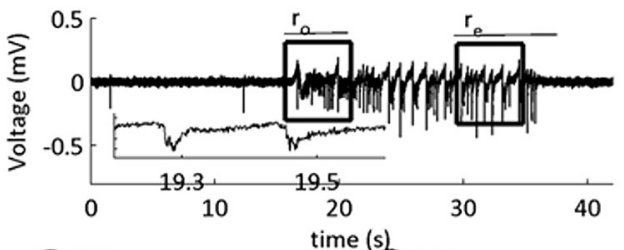

C
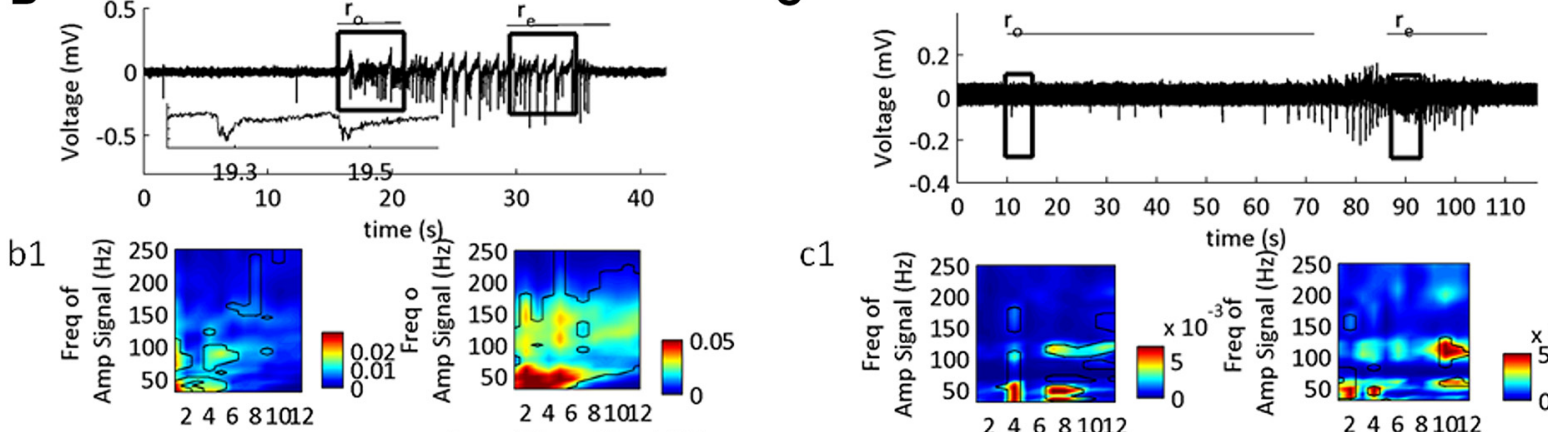

c1

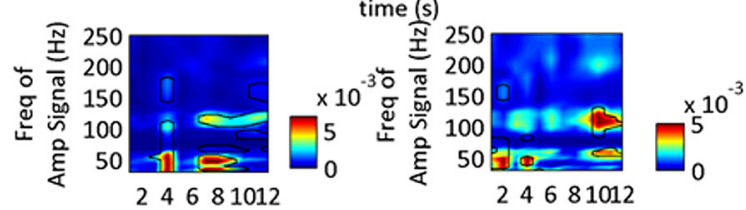

b2

$$
\text { Freq of Phase Signal }(\mathrm{Hz}) \quad \text { Freq of Phase Signal }(\mathrm{Hz})
$$

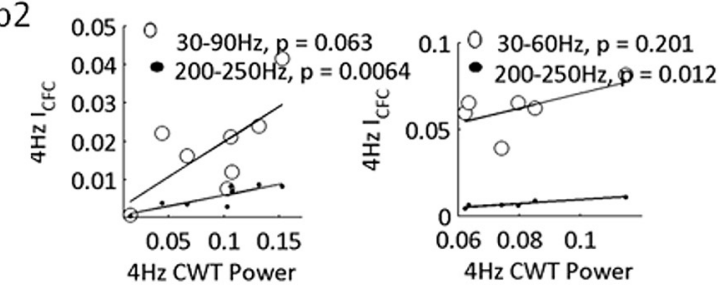

c2

$$
\text { Freq of Phase Signal }(\mathrm{Hz}) \quad \text { Freq of Phase Signal }(\mathrm{Hz})
$$

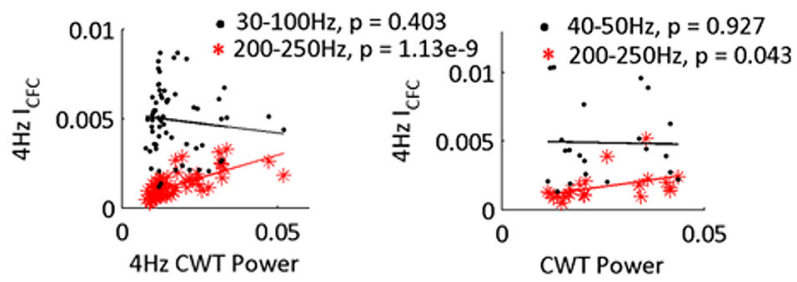

Figure 9. 


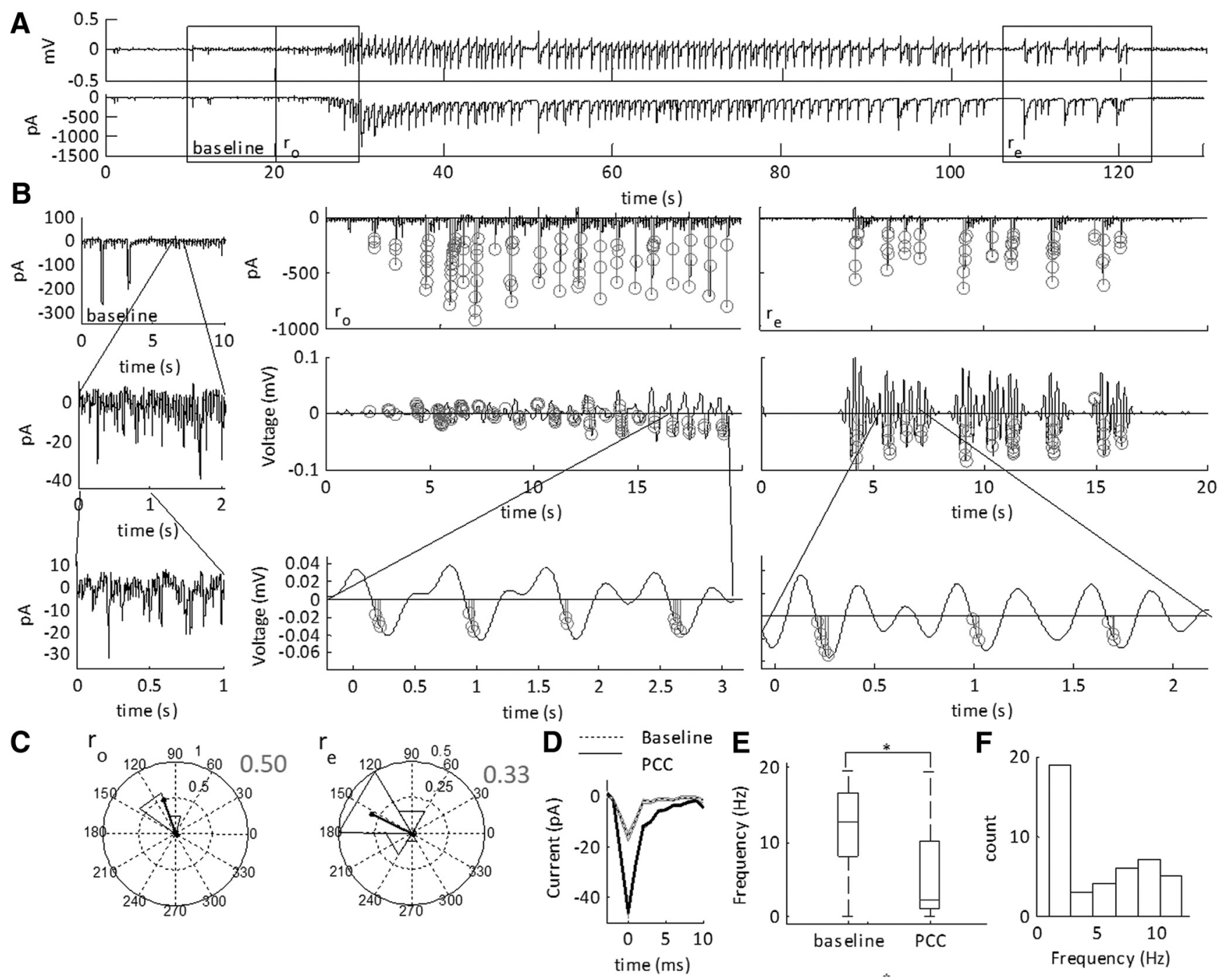

Figure 12. 